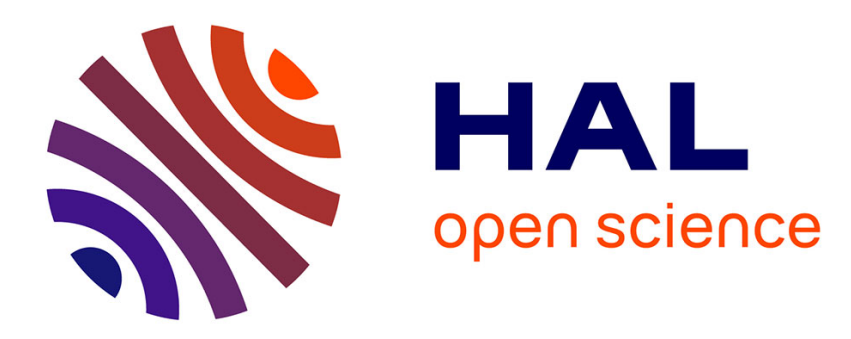

\title{
Early stages of fatigue damage in aluminium and aluminium alloys
}

R. Fougeres

\section{To cite this version:}

R. Fougeres. Early stages of fatigue damage in aluminium and aluminium alloys. Journal de Physique IV Proceedings, 1993, 03 (C7), pp.C7-669-C7-678. 10.1051/jp4:19937106 . jpa-00251723

\section{HAL Id: jpa-00251723 https://hal.science/jpa-00251723}

Submitted on 1 Jan 1993

HAL is a multi-disciplinary open access archive for the deposit and dissemination of scientific research documents, whether they are published or not. The documents may come from teaching and research institutions in France or abroad, or from public or private research centers.
L'archive ouverte pluridisciplinaire HAL, est destinée au dépôt et à la diffusion de documents scientifiques de niveau recherche, publiés ou non, émanant des établissements d'enseignement et de recherche français ou étrangers, des laboratoires publics ou privés. 


\title{
Early stages of fatigue damage in aluminium and aluminium alloys
}

\author{
R. FOUGERES
}

INSA de Lyon, Laboratoire GEMPPM, URA 341 du CNRS, Villeurbanne, France

\begin{abstract}
$\underline{\text { Abstract }}$
In this paper fatigue damage initiation is considered as both microcrack nucleation from microheterogeneities within fatigued material and microcrack growth over distances corresponding to the size of the microstructure. A brief review of the literature shows that, depending on fatigue conditions and microstructure three different types of nucleation sites exist in aluminium and aluminium alloys : slip bands, grain boundaries and brittle particles. In the last part of this paper tentative to obtain a general view of fatigue damage initiation is made from theoritical considerations taking into account incompatibility problems between matrix and microheterogeities.
\end{abstract}

\section{I - Introduction}

Fatigue damage of metals and alloys involves complex phenomena arising at different scales in the cycled materials. With time, the aircraft industry has become more demanding with respect to fatigue properties of high strength aluminium alloys. This has caused many research activities in order to understand the dependence of fatigue strength with microstructural properties. In the same way, fundamental studies have been developed in order to understand fatigue damage of pure metals. From a general point of view, fatigue damage in mechanically loaded metallic materials is relevant to three successive phases leading to the macroscopic failure of specimens [1], [2]. Firstly, at a given number of fatigue cycles, microcracks are nucleated in relation with microstructural heterogeneities in the material. This nucleation sequence is the result of previous cyclic plastic deformations which exhibit local or general aspects according to the amplitude of he applied stress. Plasticity during the cyclic deformation has been extensively studied in pure metals and alloys (see for instance [3] to [7]). These phenomena, occuring before a microcrack appears, can be considered as a preliminary phase of the fatigue damage. It has to be noticed that microcrack nucleation corresponds to atomic decohesions which require very high stress level of about E/5 [8], E being the Young modulus of the region where the microcrack is nucleated. Such a stress level, much higher than this of the applied stress, indicates that stress amplifiers exist within the material. They are due to the presence of microstructural heterogeneities associated with the development of cyclic plasticity. Secondly, as the cyclic number is increased, microcracks grow from a micrometric or submicrometric size up to a millimetric dimension. This small crack growth sequence is strongly affected by microstructural parameters and environnemental effects. This lead to a non monotic evolution of the small crack growth rate [2]. This two first fatigue damage sequences are generally considered as the initiation of the fatigue damage. Finally the ultimate phase of the fatigue damage corresponds to the growing of a macroscopic crack. Depending on the amplitude of the applied stress the crack growth can be due to the developement of a single microcrack or to the junction of several microcracks together.

In this paper attention will be focused on the phase of fatigue damage initiation i.e. the phase 1 and 2 previously described. Moreover, environnemental effects will not be considered and only fatigue damage initiation due to mechanical sequences will be analysed. A brief review of microstructural phenomena involved in the fatigue damage initiation will be firstly presented in the case of pure aluminium and high strength aluminium alloys. As a conclusion of this first part, opened questions in the domain of fatigue damage initiation and fatigue microstructures will be discussed. In the second part a contribution to experimental and theoritical problems will be given in order to attempt to obtain a general view of fatigue damage initiation in aluminium and aluminium based alloys. 


\section{II - Phenomenology of fatigue damage initiation}

In macroscopically homogeneous materials fatigue cracks nucleate from the free surface of cycled specimens. The nucleation is controlled by the plastic deformation. Therefore it can be expected that the nucleation occurs at positions where the cyclic plastic deformation is higher than average, that is to say in places where there are plastic strain concentrations [9]. From a general point of view there are three types of sites where microcracks can nucleate :

- slip bands : These sites are observed both in pure metals and alloys. They correspond to strain concentration regions where the dislocation mobility is very important owing to the presence of specific dislocation configurations in pure metals [9], [10] and shearable precipitates in alloys [5], [7], [8].

- Grains boundaries : (GB) Nucleation at GB can result from the interaction of slip bands with GB or can be due to an intensive slip activity ocurring at GB as it is generally observed at high testing temperatures.

- Inclusions; these nucleation sites are frequently observed in aluminium alloys. As a matter of fact there are secondary phases which result from heat treatments of high strength aluminium alloys having a complex chemical composition [10].

Small fatigue crack growth have been frequently studied on compact tension specimens near the threshold crack growth. Their unusual fatigue crack growth rate behaviour have been mainly analysed in terms of crack closure contribution. Closure effects are believed to occur as a result of [11] : plasticity at the crack tip asperities in the crack wake from oxides or corrosion products, crack surface roughness and phase transformations of the material ahead the crack tip. In a recent paper A.K. VASUDEVAN et al [12] claim that the behaviour of fatigue small cracks can be understood without involving crack closure effects but by considering two critical stress intensity parameters : the cyclic stress and the maximum stress intensity criteria. Such approaches are mainly relevant to mechanical concepts and the role of microstructural parameters such as grain boundaries, cristallographic orientation or precipitates, is difficult to analyze. Therefore it is necessary to give more details on the effects of microstructure on both nucleation and microcrack growth. This will be successively done for pure aluminium and high strength aluminium alloys.

\section{II.1- Pure Aluminium}

In the case of pure metals a lot of works have been devoted to copper single crystals and polycrystals. It is usually admitted that microcrack nucleation appears at the crossing of persistent slip bands (PSB) with the surface of the copper single crystal where there are stress concentrations favourable to microcrack nucleation. Crack nucleation at PSB have to be correlated with the fact that the irreversibility factor seems to be higher within PSB than in the surrounding matrix [13] and therefore could introduce a high density of accumulated dislocations. On the opposite few works have been done on aluminium.single crystal. Recently ALHAMANY et al [14] gave a detailed description of microcrack nucleation and failure in aluminium single crystals oriented for single slip and cycled at room temperature. Figure 1 shows the peak stress evolution versus the cycle number.

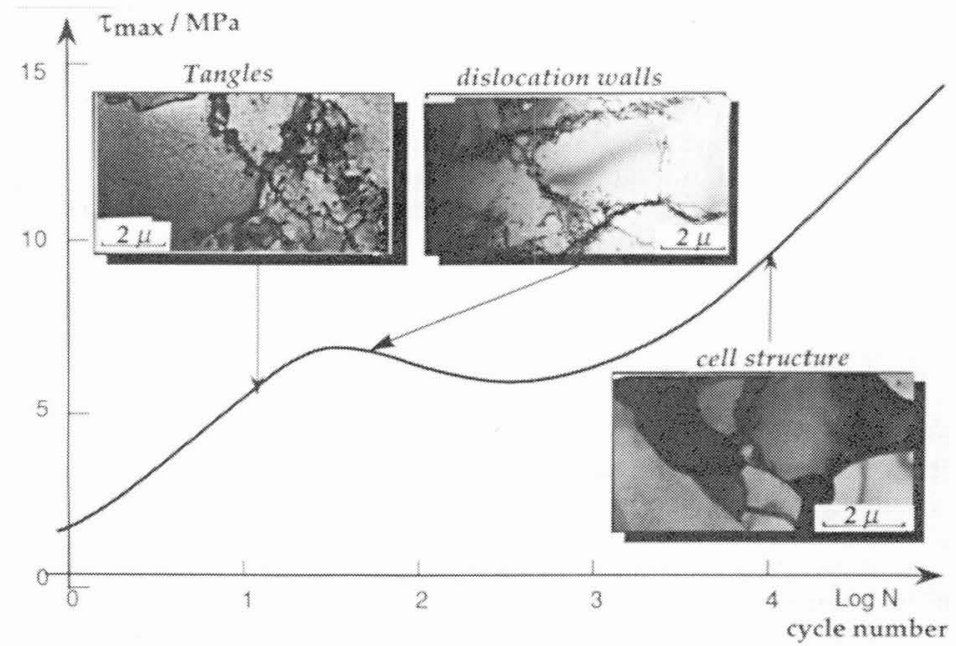

Figure 1 : Cyclic hardening of an aluminium single crystal oriented for single slip. Peak stress versus cycle number and dislocation configurations $\Delta \varepsilon^{\mathrm{P}}=2 \times 10^{-3}$. 
Three successive stages can be observed : primary cyclic hardening, cyclic softening and finally secondary cyclic hardening. In this last domain the cyclic plastic strain is concentrated in PSB which are composed of elongated dislocation cells (figure 2).
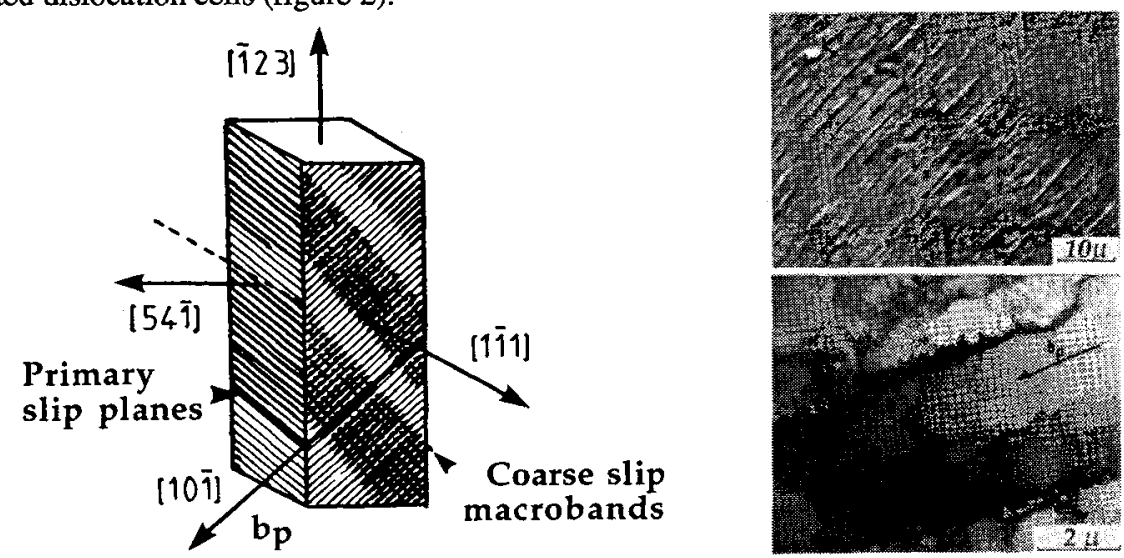

Figure 2 : Persistent slip bands in $\mathrm{Al}$ single crystal oriented for single slip. Note macrobands and intrusions extrusions. Macrobands are composed of elongated dislocation cells.

The surrounding matrix exhibits a very small plastic deformation activity. PSB are amalgamated according to macrobands as it was already observed [15]. They correspond to a slip reinforcement of the primary slip system on face (111) of the single crystal. Macrobands are aligned according to the direction defined by the crossing of the secondary slip plane with the crystal surface. Profile of a PSB on the (111) face of the single crystal has been measured by means of an Atomic Force Microscope. Figure 3 shows the profile of a PSB according to two directions defined in figure 3.
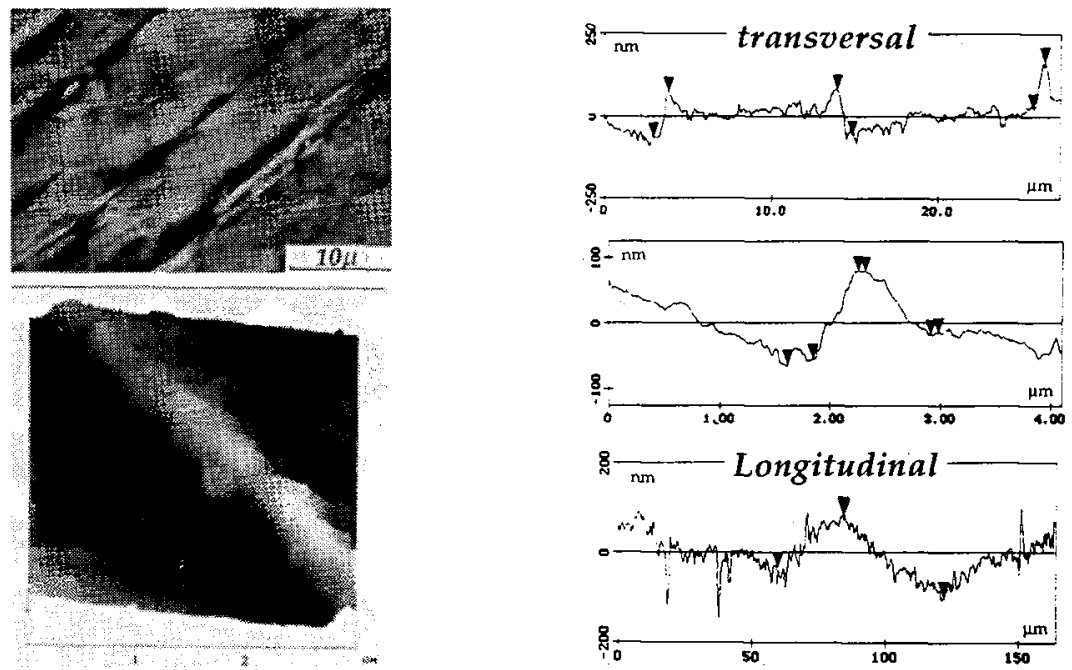

Figure 3 : Intrusions and extrusions observed by means of SEM and AFM. Profile of the intrusionextrusion observed at the surface of single crystal according to both transversal and longitudinal direction.

Extrusion and intrusion as associated companions are clearly shown in figure 3 . The width of a PSB (see direction XX' in figure 3 ) corresponds approximatively to twice times the width of a dislocation cell ( $4 \mu \mathrm{m})$. Microcracks are firstly nucleated on face (1Ii) of the single crystal at the interface between a PSB and the matrix (figure 4). From figure 4 it seems that a microcrack of $2 \mu \mathrm{m}$ long first nucleates in the intrusion region. Thus, there is a sequence of aligned microcracks along the crossing direction of the secondary slip plane with the crystal surface. The macroscopic failure of the single crystal is reached by joining nucleated microcracks together. The macroscopic failure surface of the single crystal is approximatively parallel to the secondary slip plane. 

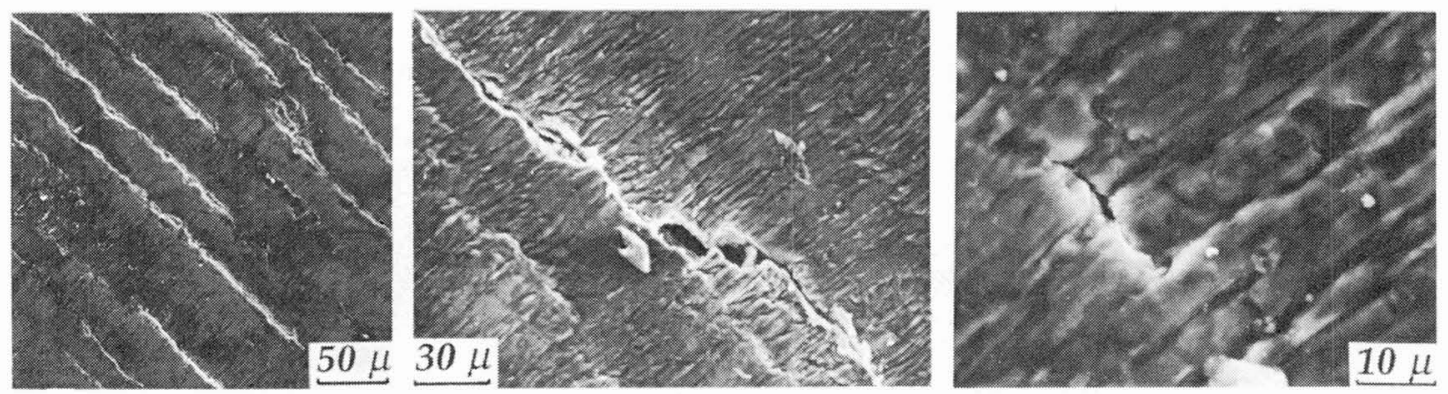

Figure 4 : Crack initiation along persistent slip band alignements.

In the case of polycrystalline cycled aluminium, microcracks nucleate at grain boundaries as a result of the interaction of transgranular persistent slip bands with grains boundaries [fig.14]. Final rupture occurs also by joining microcracks together.

\section{II.2.- High strength aluminium alloys :}

In this case, the three previously mentionned nucleation sites are observed : slip bands, grain boundaries and secondary intermetallic phase particles. The opportunity for a microcrack to nucleate at one of these three sites appears to be dependent on both cyclic loading and microstructural parameters. P. LI et al [16] have observed in the case of an Al-7075 T6 alloy that the favoured site varied with strain amplitude and temperature. Under predominantly elastic strains, debonding and cracking of secondary intermallic phases prevailed. Under applied high strain conditions, GB microcracks are formed. Moreover transgranular crackings occur in all tested specimens with a fraction of intergranular crackings increasing with temperature and strain amplitude. It seems that the slip band crack initiation is favoured in alloys without hardening precipitation. As a matter of fact, in an as solution treated 7475 alloy, H.T. JAHN and J. IN LUO [17] have observed fatigue cracks initiated at slip bands. After ageing the fatigue specimen, fatigue cracks are rather initiated at secondary phases. Despite the fact that in high purity 7010 alloys the volume fraction of secondary phases is reduced, fatigue cracks still nucleate at these particles. Figure 5 shows two crack initiation sites : $\mathrm{Mg}_{2} \mathrm{~S}_{\mathrm{i}}$ and $\mathrm{Al}_{7} \mathrm{Cu}_{2} \mathrm{Fe}$ secondary phases which lead to crack nucleation by debonding and cracking respectively.

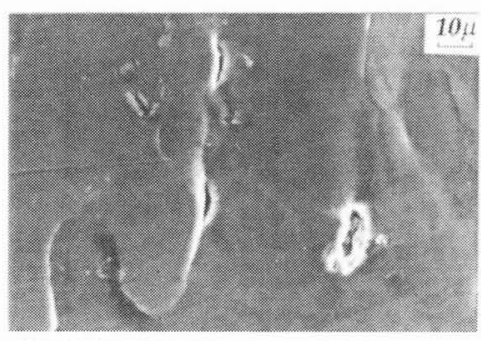

GRAIN BOUNDARY DECOHESION

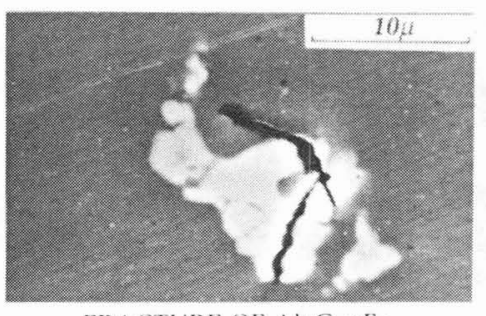

FRACTURE: OF AI7CU2Fe INTERMETALLIC

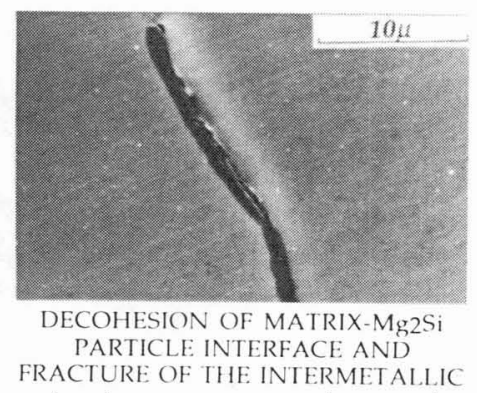

Figure 5 : Three different crack initiation sites during fatigue in 7010 aluminium alloy. Fatigue ratio $\mathrm{R}=0,1 ; \sigma_{\max }=240 \mathrm{MPa}$.

Frequently the crack nucleation appears at clustered secondary phases (fig. 6). As it is generally observed in cyclic Al-Li based alloys [18] the presence of planar slips contribute in favouring the crack initiation at grains boundaries. This probably results from the creation of dislocation pile ups at grain boundaries. But also the reversibility of the dislocation movement could be more important in the case of plastic deformations occuring by planar slips [19]. Finally the coarse aspect of slip bands in Al-Li alloys can also greatly contributes to crack nucleations at grain boundaries by increasing the number of dislocations in pile ups. In the case of the 7000 serie alloys, slip bands are more homogeneously distributed and therefore the plastic deformation in a given slip band is not so high. This is illustrated in figure 7 where is reported the profile of slip bands emerging from the surface of an Al-7010 grain located in the vicinity of a fatigue crack [20]. The height of the emerging slip bands is very small, about $20 \mathrm{~nm}$ compared with the ones observed in Al-Li alloys (up to $400 \mathrm{~nm}$ ). Therefore in this 7000 series case, the crack nucleation is mainly at secondary phases. 

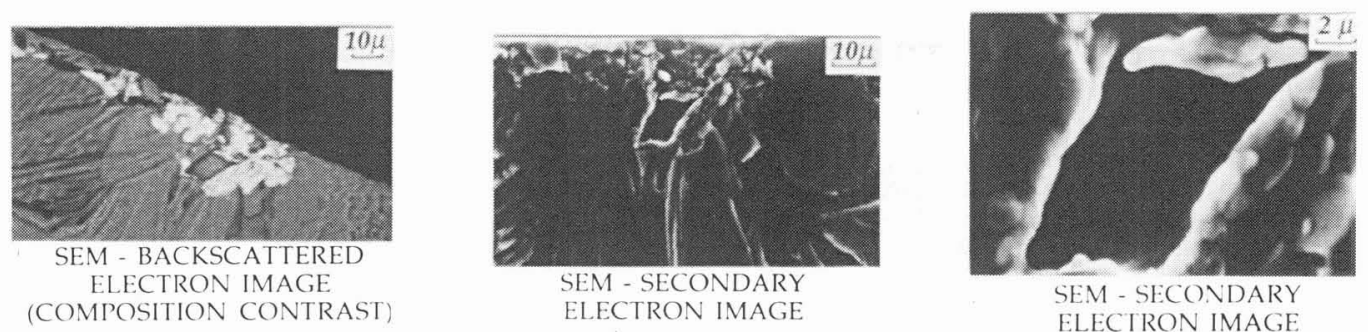

Figure 6 : Crack initiation from fracture of a cluster of intermetallic secondary phases in fatigued 7010 aluminium alloy; fatigue ratio $\mathrm{R}=0,1 ; \sigma_{\max }=290 \mathrm{MPa}$. Fracture plane is in long - long transverse directions.
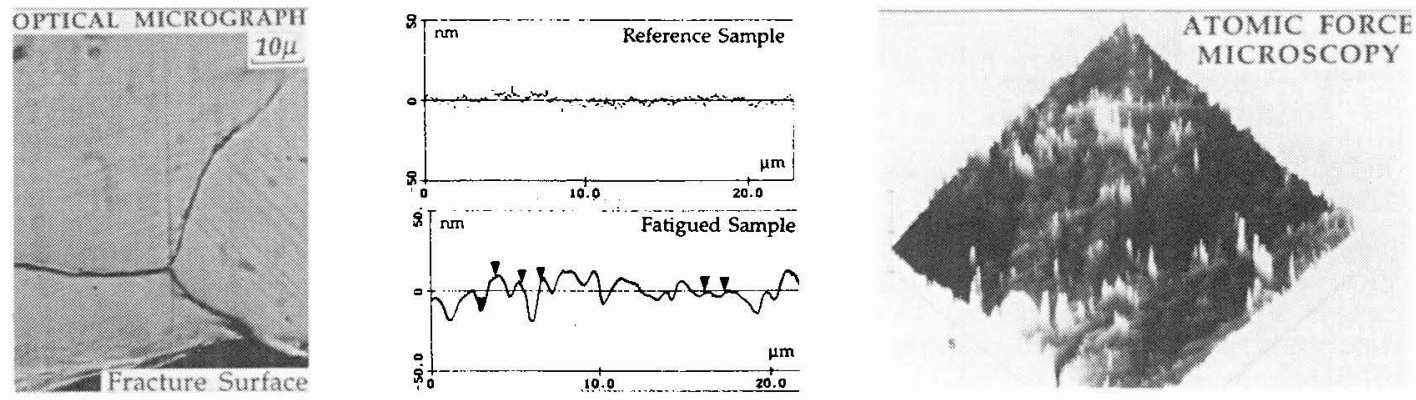

Figure 7 : Atomic force microscopy observation of a $7010 \mathrm{Al}$ allmot sample fatigued to failure : $R=0,1$; $\sigma_{\max }=290 \mathrm{M} \mathrm{Pa} ; \mathrm{NR}_{\mathrm{R}}=71000$ cycles. Profile of the grain surface at the fracture surface. Note the small height slip steps.

Once microcrack is nucleated a short crack growth domain is developed. Both intergranular and transgranular cracks are observed. For transgranular mode Q. CHEN and H.W. LI [21] have recently given a clear view of fatigue crack growth mechanisms in large grain Al 7029 aluminium alloys. Fatigue crack growth is caused primarily by shear decohesions at the crack lip. Shear decohesions could be controlled by the resolved shear stress on the active slip systems. If the resolved shear stress intensity coefficient (RSSIC) of a single slip system is much higher than all the others, shear decohesion takes place on the slip plane and the shear decohesion plane will be the crack plane. If RSSIC of two slip planes are higher than the others the alternate shear decohesions on these two planes causes a crack to grow. An another micromechanism for crack growing has been observed by D. RHODES et al [22] in 7010-T76 aluminium alloys. It corresponds to the ductile tearing resulting from the coalescence of voids which may form by decohesion or fracture of non deformable particles such as secondary phases within the metal.

Dispersoid particles can also affect the crack growth rate. M. HARRISON and J.W. MARTIN [23] observed that large $\mathrm{Mn}$ dispersoïds lower the threshold stress intensity factor while large sized $\mathrm{Zr}$ dispersoïds increase it. Benefic effects of $\mathrm{Zr}$ dispersoïds are probably due to a better homogenization of slip. As a matter of fact when very small shearable $\mathrm{Zr}$ dispersoïds are present, planar slips are enhanced and the threshold stress intensity factors reduced.

The fatigue crack growth in new OSPREY Al-Si-Fe alloys [21] originate in joining microcraks together. Microcracks are nucleated at silicon particles near the crack tip by means of shear decohesions along grain boundaries and interfaces between the aluminium matrix and iron phases. Owing to the small grain size and the high volume fraction of iron phases the distance for a crack to grow becomes very long and this greatly contributes to the high level of fatigue limit in these new alloys (ratio of fatigue limit to ultimate strength is 0.41).

Secondary intergranular cracks are common features on the fracture surface of high strength aluminium alloys. In figure $8 \mathrm{~b}$ we can see such secondary cracks on the fracture surface of a cycled Al-7010 alloy. Secondary cracks appear at grain boundaries between recrystallised and unrecrystallised grains. H.X. LI and C.Q. CHEN [25] claim that secondary crack phenomena are the result of sufficiently high triaxial tensile stresses developed within the plastic zone ahead of a crack tip. As a matter of fact triaxial stress field at the crack tip is a very important factor, but we think that in addition, G.B.secondary cracks require 
preliminary G.B dormant microcracks in order to develop. This is shown in figure 8a where a microcrack can be observed at a G.B parallel to the tensile axis. Such a phenomenon has been previously observed in a $8090 \mathrm{Al}-\mathrm{Li}$ alloy where very extended G.B secondary cracks are developed [26] and enhanced by large sized G.B. precipitate free zone.

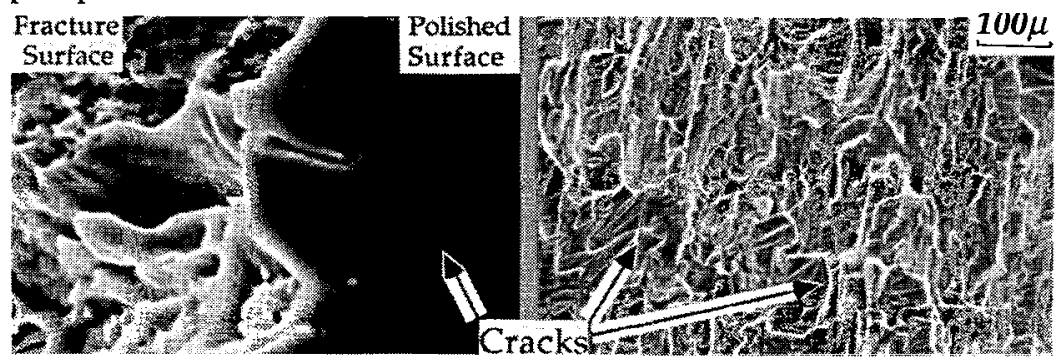

Figure $8:$ a) note in tilted view the microcrack at the grain boundary below the fracture surface.

b) secondary intergranular cracks at the fracture surface of a fatigued $7010 \mathrm{Al}$ alloy.

\section{Discussion}

From this brief review of fatigue damage initiation, general considerations are suggested whatever the investigated materials. Cycled materials can be considered to be composed of microheterogeneities (inclusion from an ESHELBY. point of view) resulting from either preliminary elaboration processes and thermal treatments of materials (secondary phases, large sized precipitates, grain boundaries, dispersoïds...) or cyclic process (slip bands). The microheterogeneities and the surrounding matrix exhibit differences in mechanical and physical properties which induce strain and stress incompatibilities from continuum mechanics point of view. In the case of secondary and dispersoïd phases, incompatitbilities originate from differences in thermoelastoplastic properties between inclusions and matrix. Slip bands incompatibilities are due to differences in plastic behaviour between persistent slip bands and the weakly plastically strained matrix. Therefore the following scheme can be proposed for fatigue damage initiation.

- As a result of stocked elastic energy and stress concentrations [27] due to incompatible stress-strain fields microcracks nucleate within microheterogeneites or at their interfaces with the surrounding matrix.

- Microcracks grow by transgranular or intergranular shear decohesions ahead microcrack tips and the propagation of a crack is the result of microcrack joinings, according to shear decohesion bands. This occurs in pure aluminium single crystals as well as in aluminium alloys. At a microscopic level the shear decohesion growth can be also due to junction of microvoids induced by the shear band at microscopic phases such as dispersoïds and incoherent precipitates. These mechanisms leading to microvoid formation are similar to those implied in the first step of fatigue damage initiation. However the applied stress field is not homogeneous but exhibits a strong gradient due to the singularity at the crack tip.

From micromechanics and physical metallurgy concepts, both damage nucleation and small crack growth can be modelized. For instance, for ten years T. MURA and collaborators [28] [29] have developed models for fatigue damage nucleation. By considering emitted dislocations at the tip of nucleated cracks, the rate of the crack growth has been calculated as a function of microstructural and crack size parameters [30] [31]. However only a poorly knowledge of microheterogeneity properties is today available and numerous questions are still opened.

- What are the exact values of thermomelastic constants of microheterogeneites such as secondary intermetallic phases or precipitates?

- Plastic strain incompatibilities result from differences in plastic strain between microheterogeneities and the surrounding matrix. An important part of fatigue plastic strains can be assumed by means of reversible movements of dislocations without increasing the plastic strain incompatibility, that is to say, without increasing the level of the stored energy or the stress concentration factor. The knowledge of the irreversibility factor (ratio of the irreversible shear plastic strain to the applied shear plastic strain) is rather a difficult parameter to reach.

- As a result of a simple approach, incompatible strains are assumed to be elastically relaxed. In fact plastic relaxation can also occurs in the matrix near-microheterogeneities as well as during mechanical loadings or previous thermal treatments. 
- Generally, intermetallic secondary particles are not distributed at random in the matrix.Secondary phase clusters consisting of two or three intermetallic particles are frequently observed in aluminium alloys. What are the effect of such clusterings on the fatigue damage initiation?.

The obtention of quantitative data on those debatable points is requiered in order to reach a better understanding in the microstructural mechanisms and to promote an accurate modelling of the fatigue damage initiation.

\section{IV - Modelling considerations}

In the last part of this paper theoritical considerations will be done on microcrack nucleation and junction modellings. Only aspects involving stored energy will be considered. Experimental estimations of different microheterogeneity properties will be also given.

\section{IV.1- Damage nucleation}

When a given heterogeneous microheterogeneity having a volume $\mathrm{V}$ is submitted to an applied stress field $\sigma A_{i j}$, the elastic energy stored within the microheterogeneity can be given from T. MURA [31] by the following equation :

$$
\left.W e l=\frac{V}{2}\left[\sigma_{i j} A\left(\varepsilon^{A}{ }_{i j}+\varepsilon_{i j} A T e q\right)-\sigma_{i j} I_{\left(\varepsilon_{i j}\right.} T^{T} \text { Teq }+\varepsilon_{i j} P \text { Teq }\right)\right]
$$

$\varepsilon_{i j} \mathrm{~A}$ is the strain field corresponding to the applied stress tensor $\sigma_{\mathrm{ij}} \mathrm{A}, \delta_{\mathrm{ij}} \mathrm{ATeq}$ is the equivalent free transformation strain (EFTS or eigeinstrain) due to the elastic heterogeneity, $\sigma_{\mathrm{ij}} \mathrm{I}$ is the stress tensor whitin the microheterogeneity, $\varepsilon_{\mathrm{ij}} \mathrm{T}$ Teq and $\varepsilon_{\mathrm{ij}} \mathrm{P}$ Teq the EFTS tensors corresponding to plastic and thermal heterogeneities, respectively.

In the case of cyclic deformations the plastic EFTS tensor $\varepsilon_{\mathrm{ij}} \mathrm{P}$ Teq have to be discussed. For push-pull fatigue tests we can consider that the component of the $\varepsilon_{\mathrm{ij}} \mathrm{T}$ Teq tensor can be deduced from the cumulated plastic deformation multiplied by the irreversibility factor if this last parameter is assumed to be cycle number independent. In the case of cyclic tests conducted with a fatigue ratio $R$ such as $R>0$, the $\varepsilon_{i j} P$ Teq tensor components can be calculated from the measured remanent strain of the cycled samples.

Now we are going to see different examples showing the role of several types of heterogeneities.

\section{IV.1.1.Plastic heterogeneity : aluminium single crystal case.}

The stored energy in a persistent slip band of a cycled aluminium single crystal can be calculated by means of the equation (1).We can consider that in equation (1) the only eigenstrain term (non equal to zero) is $\varepsilon_{\mathrm{ij}} \mathrm{P}$ The volume $\mathrm{V}$ corresponds to the volume of the persistent slip band. As shown in figure 3 an ellipsoìd volume of $30 \times 30 \times 2 \mu \mathrm{m}^{3}$ seems to be a good choice for the volume V. From results presented in figure 3 it is possible to calculate the irrerversibility factor P. As a matter of fact, the increasing height of the PSB step at the (111) surface of the single crystal after adding 1000 fatigue cycles, is by $50 \mathrm{~nm}$. By taking both usual geometrical parameters and the applied plastic strain amplitude into account, the irreversibility factor $\mathbf{P}$ is found to be $1.5 \times 10^{-3}$. At the $80,000^{\text {th }}$ cycle, where microcracks are initiated under fatigue conditions defined in figure 3 , the eigenstrain $\varepsilon_{i j} \mathrm{P}$ in PSB, taking into account both irreversible plastic deformations due to previous cycles and the plastic strain field due to the applied tensile peak stress, is given by :

$$
\varepsilon_{11}=-0,810^{-3}, \quad \varepsilon_{22}=\varepsilon_{33}=0,4410^{-3}, \varepsilon_{12}=0, \varepsilon_{13}=-2,410^{-3}, \varepsilon_{23}=-1,3810^{-3}
$$

With equation (1) the stored energy is $\mathrm{W}_{\mathrm{el}}=4.8 \times 10^{-2} \mathrm{~J}$. By considering that this energy is dissipated to create two surfaces of $30 \times 2 \mu \mathrm{m} 2$ in order to create microcracks at the end of PSB (see fig.3) we find an energy $\gamma$ of $0.72 \mathrm{~J} / \mathrm{m}^{2}$ for creating a unit surface in aluminium. This value is in good agreement with that given by FRIEDEL [8]. $\left(\mu \mathrm{b} / 10=0,8 \mathrm{~J} / \mathrm{m}^{2}\right)$.

\section{IV.1.2- Plastic relaxation of thermal and plastic incompatibilities}

In equation (1) only elastic relaxations are considered. As a matter of fact a part of incompatible strains is frequently relaxed by means of matrix plastic strain around the particles. For instance in the case of an Al-Si $\mathrm{Fe}$ alloy quenched from a temperature of $520^{\circ} \mathrm{C}$ down to the room temperature the effective temperature gap 
that must be considered for calculating the thermal egeinstrain in equation (1) is only $90^{\circ} \mathrm{C}$ [32]. This small temperature gap have been calculated by considering emitted dislocations in the matrix during the quenching according to the HAMANN et al's model [33]. This has been found in good agreement with the difference observed at the proportional elastic limit from tension and compression tests [34]. In the case of a cycled 7010 aluminium alloy with accumulate plastic strain of $0.3 \%(R=0.1)$ the figure 9 represents the plastic strain field around a $\mathrm{Mg}_{2} \mathrm{Si}$ particle. These plastic deformations have been calculated from the deformation of gold microgrids deposited at the surface of the fatigue samples before cycling. We can see that near the $\mathrm{Mg}_{2} \mathrm{Si}$ particles there is a very important excess of plastic deformation mainly in the direction of the applied tensile load.

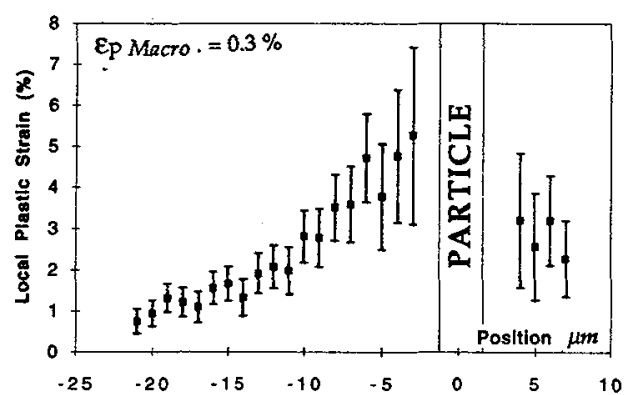

Figure 9 : Plastic deformation around particles according the tensile direction after 10 cycles. Surface of a $7010 \mathrm{Al}$ alloy sample. $\mathrm{R}=0,1 ; \sigma \max$ $=440 \mathrm{MPa}$. Note the Mg2 Si particles.

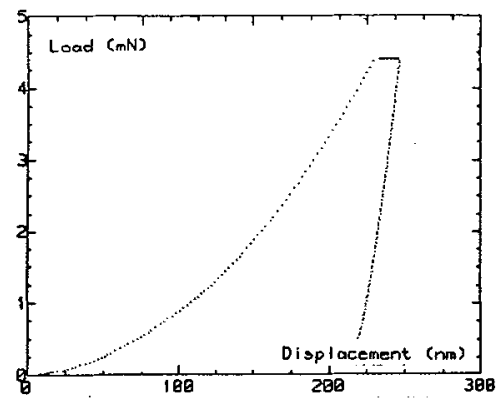

Figure $10:$ Measurement of microheterogeneity young's modulus from the load displacement curve during a nanoindentations experiment. Case of a Si particle in an $\mathrm{Al}-\mathrm{Si}-\mathrm{Fe}$ osprey alloy. Young's modulus is measured at the unloading.

\section{IV.1.3.- Elastic plastic and thermic heterogeneities}

In high strength aluminium alloys the microcrack nucleation results in brittle particle cracking ( $\mathrm{Al} 7$ $\mathrm{Cu}_{2} \mathrm{Fe}_{\mathrm{e}}$ and $\mathrm{Mg}_{2} \mathrm{Si}$ in 7000 series alloys and Si particles in $\mathrm{Al}-\mathrm{SiFe}$ alloys). In order to estimate the role of the elastic heterogeneity the elastic constants of brittle particle are required. Elastic modulus can be obtained from nanoindentation technics [31]. In figure 10, the load versus displacement curve on a Si-particle is reported. Young's modulus is determined from the beginning of the unloading part of the load displacement curve. Attention has to be focussed on experimental conditions. Especially the maximum applied load must be as much as possible so that the particle can be considered as a semi-infinite volume.

The values of Young's modulus for Si particles is $160 \mathrm{GPa}$. In order to compare effects due to thermal elastic and plastic heterogenities the figure 11 shows their contributions to the stored energy in a Si particle as a function of the applied stress to an $\mathrm{Al}-\mathrm{SiFe}$ specimen cycled with a fatigue ratio $\mathrm{R}=0.1$ (results are for the first cycle). We can see that the main contribution is due to plastic heterogeneity.

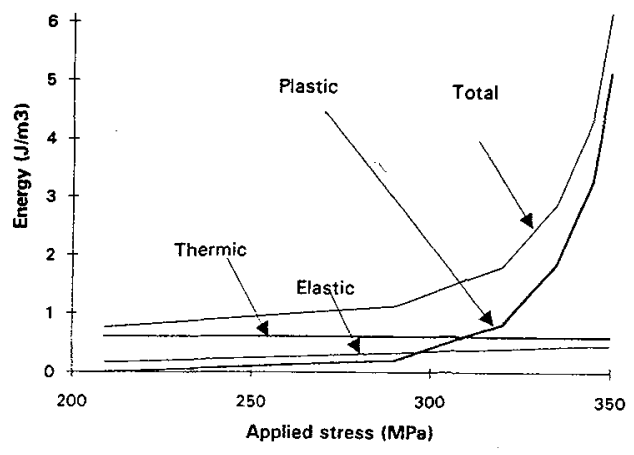

Figure 11 : Differents contributions to the elastic stored energy Al-Si-Fe case. $\mathrm{R}=0.1$. Results after the first fatigue cycle.

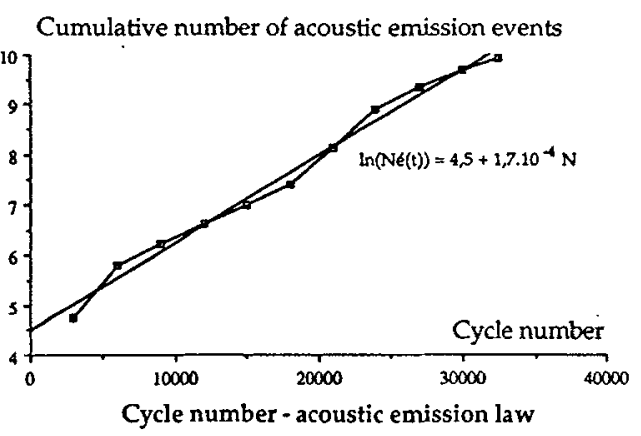

Figure 12: Cumulated number of acoustic emission events versus the cyclic number. Note the variation of the experimental values according to a straight line. 


\section{IV.2.- Microcrack junction: Al-Si Fe alloy case [34]}

Just after the fatigue initiation range (cycle number $\mathrm{N}=\mathrm{Ni}$ with $\mathrm{R}=0.1$ ) there is a crack within the cycled samples having a length Lo. Due to stress concentration at the crack tip, Si particles are cracked in a region of size $\mathrm{D}$ where the stress ahead the crack tip is higher than the critical stress $\sigma_{\mathrm{A}}$ required to crack a $\mathrm{Si}$ particles. If we consider that Si particle microcracks require an increase by $\Delta \mathrm{N}$, of the cycle number for joining together within the region of size $D$, the crack length $L(N)$ at a cycle number $N$ is given by :

$$
L(N)=L_{0}\left(1+\frac{1}{2}\left(\frac{\sigma_{\max }}{\sigma^{\mathrm{A}}}\right)^{2}\right)^{N / \Delta N}
$$

where $\sigma_{\max }$ is the fatigue peak stress. In order to verify semi quantitatively the validity of the equation (2), figure 12 represents the logarithm of the cumulated acoustic emission events versus the cycle number $\mathrm{N}$. By assuming that the acoustic emission activity is proportional to the crack length, the semi logarithmic coordinates should lead to a straight line for the acoustic emission-cycle number curve according to equation (2). In figure (12) we can see that a straight line can be drawn according to the predictions.

\section{V.- Concluding remarks}

In this paper the role of microheterogeneites on fatigue damage initiation in pure aluminium and aluminium alloys has been analysed. In order to obtain a quantitative approach of the fatigue damage initiation, efforts have to be made in the following domains : characterization of physical and mechanical properties of microheterogeneities, irreversibility problems, heterogeneous distribution (spatial) of microheterogeneities, analysis of the fatigue result scattering as a result of distributed properties of the microheterogeneities (distributions in position, size, shape, physical and mechanical properties).

\section{ACKNOWLEDGMENTS}

I wish to thank A. HAMEL and G. PETTON for the fruitful discussions we had together during the writing of this publication. I am also grateful to the "Centre de Recherches de Voreppe" from the group PECHINEY, which has been supporting financially some studies, the results of which being presented in this paper. Finally, I want to precise that the AFM pictures were obtained in the "Centre ESCA de nanoanalyse et Technologie de Surface (Lyon FRANCE)" the chairman of which being Pr. TRAN MINH DUC, who is greatly acknowledged. 


\section{REFERENCES}

[1] MILLER K.J., Fract. Engng. Mater. Struc. vol 10, ${ }^{\circ} 1$ (1987) pp.75-91.

[2] KITAGAWAA H. and TAKAHASNE, Inte. Conf. Mech. behaviour of Materials (ICM2), A.S.M. (1976) pp. 627-631.

[3] MUGHRABI H, The Institute of Metals London (1985) pp. 244-261

[4] BAO TONG M.A.and LAIRD C, Acta. Metall. Vol 37 n'2 (1989) part I, pp. 325-336, part II : pp. 337348, part III : pp. 349-355, part IV : pp. 357-368.

[5] VOGEL W., WILHELM M. and GEROLD V., Acta. Metall., vol 30 (1982) pp. 21-30.

[6] PAHL R.G.Jr and COHEN J.B., Metallurgical Transactions A, vol 15A, August (1984) pp. 1519-1529.

[7] BRECHET Y., LOUCHET F., MARCHIONNI C., VERGER-GAUGRY J.L., Phil. Mag (1987) A 56, p. 353.

[8] GENTZBITTEL J.M. and FOUGERES R., Scripta. metall., vol. 21 (1987) p. 1182-1184.

[9] PETR-LUKAS., Materialkundl. Techn. Reihe Bd 9, Berlin-Stuttgart (1990) pp. 125-139.

[10] SANDERS T.H., Jr and STALEY, J.T., Fatigue and Microstructure ASM Seminar, St Louis Missouri, Ed. ASM Metalspark Ohio 44073 (1978) pp.467-521.

[11] SURESH S., Fatigue of Materials Cambridge University Press (1191).

[12] VASUDEVAN A.K., SADANANDA K. and LOUAT N.; Scripta. Metall., Vol. 28 (1993) pp. 65-70.

[13] MAGNIN T., DRIVER J., LEPINOUX J. et KUBIN L.P., Rev. Phys. Appl. 19 (1984) pp. 467-482, 483-502.

[14] ALHAMANY A., CHICOIS J., FOUGERES R.et HAMEL A., Journal Physique III, France 2 (1992) pp. 1491-1508.

[15] WORREN O. and RYUM N., Acta. Metall., Vol. 35, n 4 (1987) pp. 855-866.

[16] LI P., MARCHAND N.J. and ILSCHNER B., Mat. Sci. and Eng. A 119 (1989) pp.41-50.

[17] JAHN M.T., JIN LUO, Journal of Material Science, 23 (1988) pp. 4115-4120.

[18] BERANGER A.S., HAUTEFEUILLE L., CLAVEL M., 32ème colloque de Métallurgie, Institut National des Sciences et Techniques Nucléaires SACLAY, Juin (1989) p. 1-14.

[19] PETTON G et al, to be published.

[20] VERDU C. et FOUGERES R., Revue de Physique Appliquée 25 (1990) pp. 1095-1105.

[21] CHEN Q and LIU H.W., Theoritical and Applied Fracture Mechanics 10 (1988) pp. 111-122.

[22] RHODES D., NIX K.H. and RADON J.C., Int. J. Fatigue, Vol 6, nº 1, January (1984) pp. 3-7.

[23] HARRISON M. and MARTIN J.W., Proceeding of ICMA 7, Montreal Pergamon Press (1985) pp. 1261-1266.

[24] COURBIERE M. and MOCELLIN A., This Conference.

[25] LI H.X. and CHEN C.Q., Materials Science and Technology Vol. 6, September (1990) pp. 850-856.

[26] VERDU C.and FOUGERES R., Proceedings of Sixth International Al-Li Conference DGM Information Sgesellschaft Verlag. M. Peters and P.J. Winkler Editors, October (1991) pp. 421-426.

[27] GOODS S.H., BROWN L.M., Acta Metallurgica., vol. 27 (1979) p.1-15.

[28] VENTKATARAN G., CHUNG Y.M., NAKASSONE Y and MURA T., Acta. Metall. Mater. Vol. $38 \mathrm{n}^{\circ} 1$ (1990) pp. 31-40.

[29] MURA T., Micromechanics of defects in solids, Martinus Nishaff Publishers, Kluwer Academic Publishers Group, Boston (1987)

[30] JIA LI and LI J.C.M. Dislocations emitted from a fatigue crack I : identical Burger'sVector. Materials Science and Engineering A 129, (1990) p.p. 167-174.

[31] LI J.I.A. and LI J.C.M. Dislocations emitted from a fatigue crack. II : Burger's Vectors of both signs - Materials and Science Engineering A 129 (1990) p.p. 175-182..

[32] FANTOZZI G. et PALETTO S., Revue Scientifique et Technique de la Défense $2^{\text {nd }}$ trimestre (1991) pp. 127-130.

[33] HAMANN R. and FOUGERES R., Proceeding of the $12^{\text {th }}$ RIS $\varnothing$ International Symposium on Material Science, Risø (DK) (September 1991), pp. 373-378.

[34] HAMANN R., GOBIN P.F. and FOUGERES R., Scripta Metall. Mater., vol. 24, ${ }^{\circ} 9$ (1990) pp. 1789-1794.

[35] MOCELLIN A., BRECHET Y. and FOUGERES R., to be published. 